\title{
Regeneration of Aspergillus nidulans Protoplasts
}

\author{
By J. F. PEBERDY AND R. K. GIBSON \\ Department of Botany, University of Nottingham, Nottingham, $N G 72 R D$
}

(Accepted for publication 9 September I97I)

\begin{abstract}
SUMMAR Y
The process of regeneration of mycelial protoplasts from Aspergillus nidulans wild-type and strain P76 has been investigated. In liquid media two patterns of regeneration were observed. In the first, the protoplasts produced chains of yeastlike cells and eventually the terminal cell produced a hypha. In the second wall 'shells' were formed into which the cytoplasm migrated. It is suggested that the mechanism of regeneration reflects the site of origin of the protoplast from the parent hypha.
\end{abstract}

\section{INTRODUCTION}

Protoplasts can be isolated from filamentous fungi quite readily after treatment with lytic enzymes obtained from Streptomyces spp. and from snail gut juice. An important aspect of protoplasts lies in their potential for regenerating a normal mycelium (Emerson \& Emerson, 1958; Bachman \& Bonner, 1959; Garcia Acha, Lopez Belmonte \& Villanueva, 1966). It is suggested that this system provides a means for studying cell-wall synthesis and growth in filamentous fungi, and may ultimately lead to a knowledge of the control mechanisms involved. This report discusses the morphological changes which occur during protoplast regeneration in Aspergillus nidulans.

\section{METHODS}

Organisms. Aspergillus nidulans (Eidam) Winter wild-type strain and A. nidulans strain P76, a yellow spored, auxotrophic strain requiring proline, were used to obtain protoplasts in this investigation. Cultures were grown on malt extract agar (Oxoid) for both maintenance and for the preparation of conidial suspensions.

Streptomyces RA, kindly provided by Professor J. R. Villanueva, was used to prepare the lytic enzyme for protoplast production. The organism was grown on mycelial agar slopes as described previously (Peberdy, 1971).

Preparation of lytic enzyme. Streptomyces RA was grown on a medium (SM) containing (g./l.) $\mathrm{Na}_{2} \mathrm{HPO}_{4}$. I $2 \mathrm{H}_{2} \mathrm{O}, \mathrm{I} \cdot 8 ; \mathrm{KH}_{2} \mathrm{PO}_{4}, 0.68 ; \mathrm{MgSO}_{4} \cdot 7 \mathrm{H}_{2} \mathrm{O}, 0.5 ; \mathrm{FeSO}_{4} \cdot 7 \mathrm{H}_{2} \mathrm{O}, 0.2$; yeast extract (Oxoid), $0 . \mathrm{I}$; chitin (Sigma), 2.5 ; laminarin, $2.5 ; \mathrm{pH} 7.0$ (Nombela, Arrieta \& Villanueva, personal communication). Seed cultures, $500 \mathrm{ml}$. in 51 . flasks, were inoculated with spore suspensions and grown at $25^{\circ}$, with shaking, for 2 days and then transferred to a 101 . fermenter containing 7.51 . of medium. The culture was stirred at $750 \mathrm{rev} . / \mathrm{min}$. and aerated at $81 . / \mathrm{min}$. for 7 days at $29^{\circ}$. At harvesting, the Streptomyces mycelium was removed by filtration and the culture medium was concentrated on a rotary evaporator at $30^{\circ}$ to $\mathrm{I} / \mathrm{IO}$ volume. The concentrate was centrifuged at $15,000 \mathrm{~g}$ at $0^{\circ}$ for $30 \mathrm{~min}$. and finally passed through a sintered glass filter (porosity 5). The enzyme preparations (concentrated filtrates) were stored at $-20^{\circ}$. 
Preparation of protoplasts. Protoplasts were obtained from 24 h. cultures of both strains of Aspergillus nidulans grown on a medium (AM) containing (g./1.) glucose, I0; sodium citrate, $3 ; \mathrm{KH}_{2} \mathrm{PO}_{4}, 5 ; \mathrm{NH}_{4} \mathrm{NO}_{3}, 2 ; \mathrm{MgSO}_{4} .7 \mathrm{H}_{2} \mathrm{O}, 0.2 ; \mathrm{CaCl}_{2}, 0 . \mathrm{I}$; yeast extract (Oxoid), 0.25 . The medium was adjusted to $\mathrm{pH} 6.5$ before autoclaving. Erlenmeyer flasks $(250 \mathrm{ml}$.) containing $25 \mathrm{ml}$. medium were inoculated with I $\mathrm{ml}$. of a conidial suspension containing approximately $10^{7}$ spores $/ \mathrm{ml}$. The mycelium was harvested by centrifugation, washed with $0.2 \mathrm{M}$-phosphate buffer, $\mathrm{pH} 6.0$, and finally resuspended in the same buffer containing $0.8 \mathrm{M}-\mathrm{NH}_{4} \mathrm{Cl}$.

Mycelium suspension ( $5 \mathrm{ml}$. vol.) was incubated with $5 \mathrm{ml}$. lytic enzyme at $28^{\circ}$, with shaking, for $2 \mathrm{~h}$. The protoplasts were separated from the mycelial debris by filtration through a sintered glass filter (Jena, porosity D 2) and were collected by centrifugation at $500 \mathrm{~g}$ for $10 \mathrm{~min}$.

Regeneration studies. The protoplasts were washed three times in $0.2 \mathrm{M}$-phosphate buffer, $\mathrm{pH} 6 \cdot 0$, containing $0.4 \mathrm{M}-\mathrm{NH}_{4} \mathrm{Cl}$ and finally resuspended in regeneration medium. This was similar to AM culture medium except that glucose was at $5 \%$ and $0.4 \mathrm{M}-\mathrm{NH}_{4} \mathrm{Cl}$ was present as osmotic stabilizer. Yeast extract was omitted from the regeneration medium for wild-type protoplasts. The protoplast suspensions were incubated in small centrifuge tubes at $25^{\circ}$. Individual tubes were taken at $2 \mathrm{~h}$. intervals, centrifuged at $500 \mathrm{~g}$ for $5 \mathrm{~min}$. and the sediment resuspended in $0.4 \mathrm{M}-\mathrm{NH}_{4} \mathrm{Cl}$ in $0.2 \mathrm{M}$-phosphate buffer, $\mathrm{pH} 6.0$ and examined by phase contrast and Nomarski interference microscopy. Protoplast sediments were also resuspended

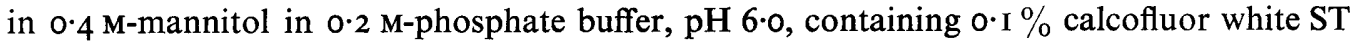
(American Cyanamid Co., Wayne, New Jersey, U.S.A.) and examined by u.v. fluorescence microscopy for the formation of walls (Nagata \& Takebe, 1970).

\section{RESULTS AND DISCUSSION}

The first observable change in the mycelium on incubation with the lytic enzyme was swelling of the hyphal tips and this was followed by the release of small $(4 \cdot 1$ to $5 \cdot 5 \mu \mathrm{m}$. diameter) nonvacuolate protoplasts about 45 to $60 \mathrm{~min}$. after the start of incubation. Continued incubation resulted in the older parts of the hyphae becoming swollen and a simultaneous appearance of larger ( $4^{\cdot} \mathrm{I}$ to $8 \cdot 2 \mu \mathrm{m}$. diameter) vacuolate protoplasts in the incubation medium. Swelling of hyphae with associated release of protoplasts was also observed in Fusarium culmorum by Rodriguez Aguirre, Garcia Acha \& Villanueva (1964). Experiments with Aspergillus nidulans, wild-type strain, suggest that protoplasts show neglible swelling after release. After I h. the suspension contained $82 \%$ of the small nonvacuolate protoplasts. These suspensions were resuspended in phosphate buffer $\mathrm{pH} 6.8$ containing $0.8 \mathrm{M}-\mathrm{NH}_{4} \mathrm{Cl}$. After a further 2 hour period the small nonvacuolate form accounted for $79 \%$ of the suspension (C. E. Buckley, personal communication).

The successive release of small nonvacuolate and of large vacuolate protoplasts may have reflected differences in susceptibility of the different regions of the hyphae to the lytic enzymes. The newly synthesized wall at the hyphal tip may have been more readily degraded than the wall in older regions. Also, the two types of protoplasts released during incubation may have differed in their potential to produce a wall and undergo regeneration. The small protoplasts released from the terminal region might have been expected to have a greater capacity for regeneration as this region of the hypha has the greater ability for wall synthesis (Zalokar, 1959). However, the fact that the vacuolate protoplasts from the older parts could also regenerate indicated that the potential for wall synthesis was not lost.

Protoplast regeneration was examined over a period of $24 \mathrm{~h}$., during which time about $50 \%$ of the protoplasts had reached some stage of regeneration. The inability of some proto- 

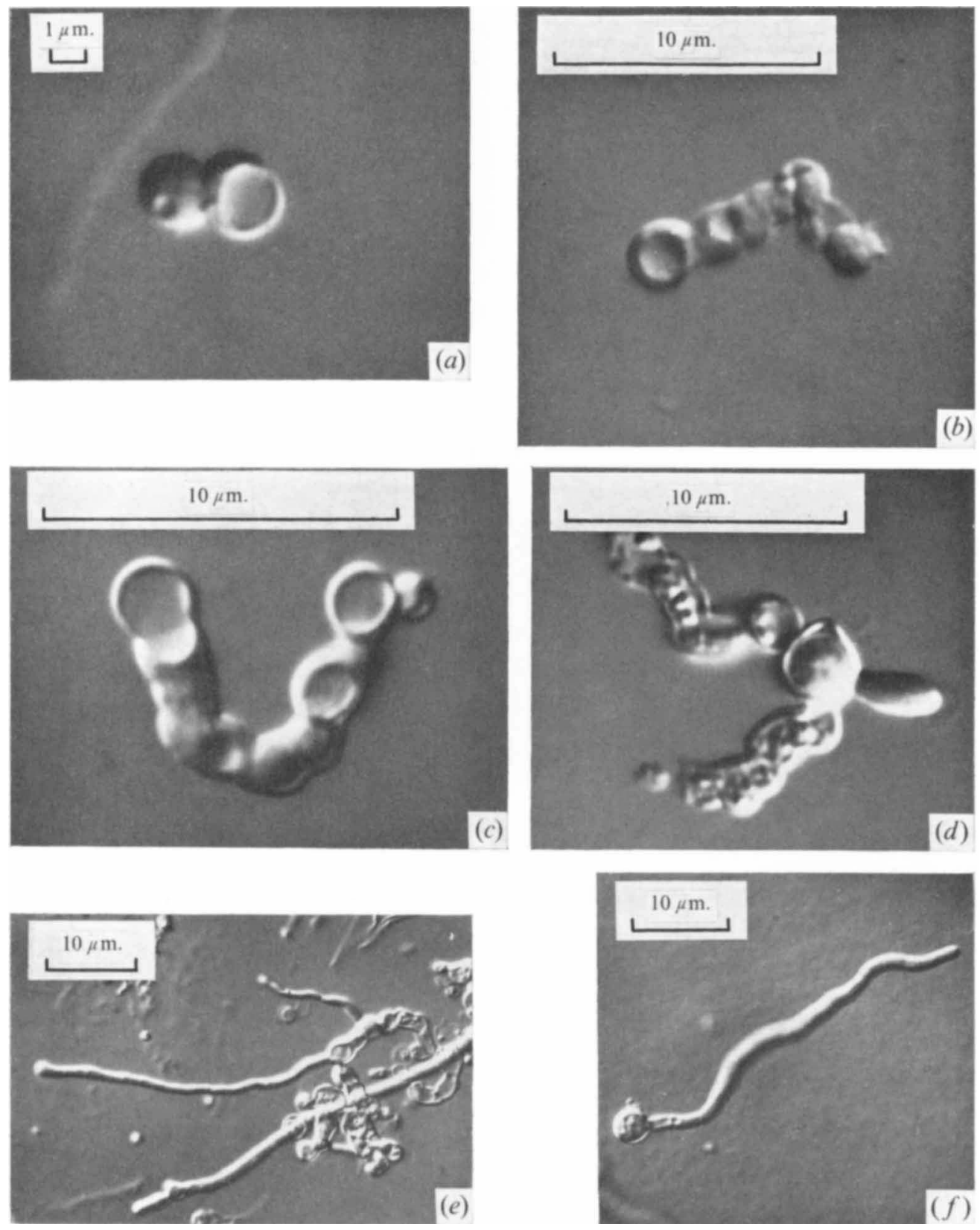

Fig. I. Protoplast regeneration in Aspergillus nidulans P 76 Nomarski interference microscopy. (a) The formation of the first yeast-like cell after $2 \mathrm{~h}$. A large vacuole is formed at this early stage. $(b)$ $4 \mathrm{~h}$. regeneration showing the establishment of a distinct chain of cells. $(c) 8 \mathrm{~h}$. regeneration. As the chain lengthens the cells develop large vacuoles. $(d)$ ro h. regeneration with the formation of the first hypha. (e) $24 \mathrm{~h}$. regeneration showing a well-developed hypha. There is no branching at this stage. $(f)$ Direct germination of a protoplast embedded in regeneration medium supplemented with $0.5 \%$ agar. $\mathrm{I} 6 \mathrm{~h}$. regeneration. 

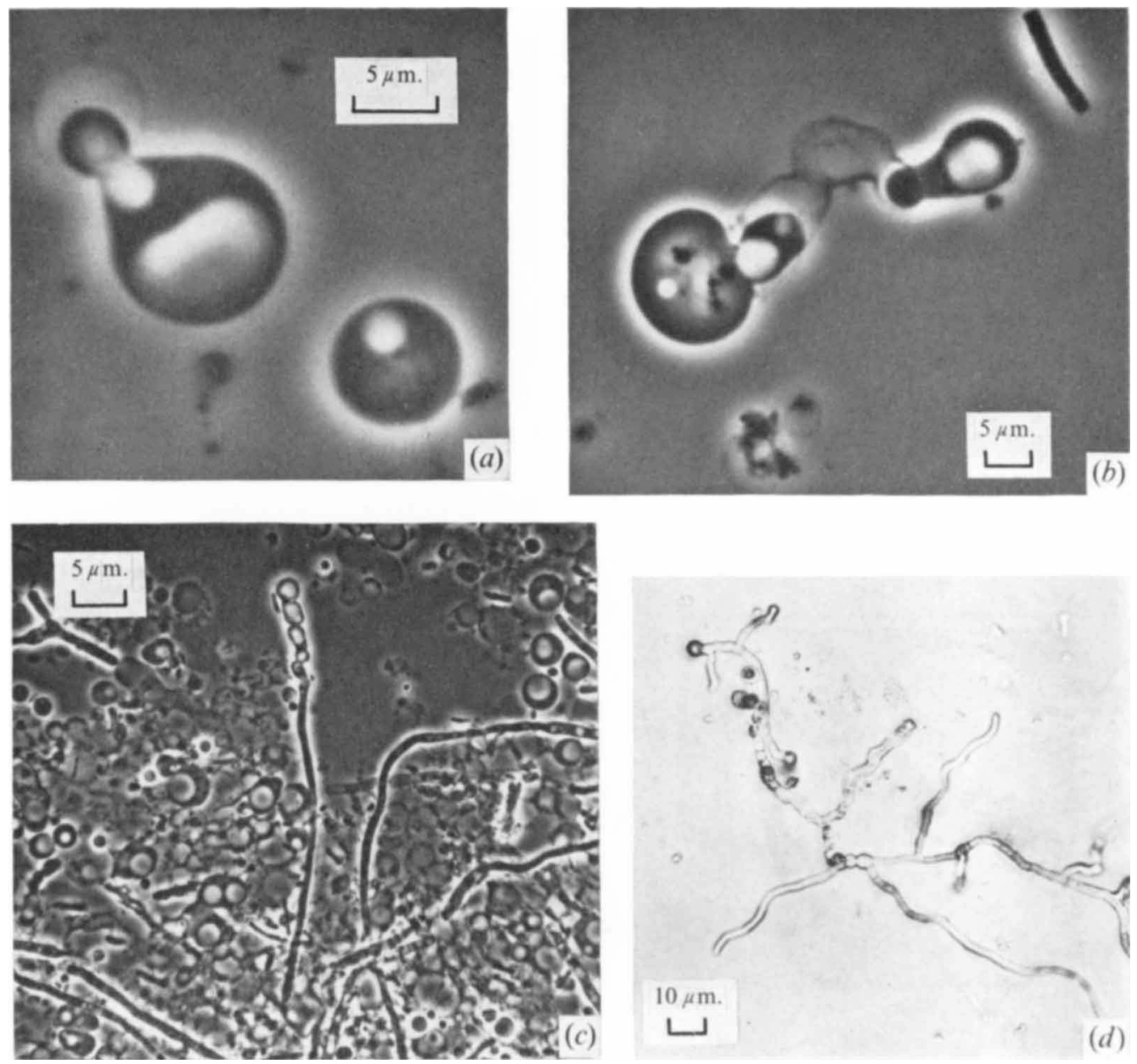

Fig. 2. Protoplast regeneration in wild-type Aspergillus nidulans. Phase contrast microscopy. (a) $6 \mathrm{~h}$. regeneration showing the formation of a wall 'shell' with the protoplast cytoplasm migrating into it. (b) $12 \mathrm{~h}$. regeneration. The cytoplasm has cleaved and the two parts are located at opposite ends of the chain. The region of empty walls between the cytoplasm is very distinct. (c) General picture of a regenerating culture after $24 \mathrm{~h}$. This indicates the differences in regeneration times of different protoplasts. Pleomorphic protoplasts are present; some of these may have arisen by fusion. $(d)$ Microcolony which has arisen from a regenerated protoplast.

plasts to regenerate may have been due to their original hyphal location, the absence of nuclei, as suggested by Garcia Acha et al. (1966), or the absence of other organelles.

Stages of protoplast regeneration are shown in Figs. I and 2 and the times indicated are the earliest at which that particular stage was observed. With strain 876 the first sign of regeneration was seen after $2 \mathrm{~h}$. but in the wild-type a lag of $6 \mathrm{~h}$. occurred. This difference may have reflected the absence of yeast extract from the regeneration medium of the latter strain. Possibly yeast extract contains growth substances of importance in wall synthesis. The population of regenerating protoplasts was heterogeneous in both the ability to regenerate and the rate of the process. Both of these differences may have been a function of the organelle constitution of the protoplasts. 
Two patterns of regeneration were observed in each strain and corresponded to two of those observed by Garcia Acha et al. (1966). In the first, the protoplasts gave rise to a chain of yeast-like cells. These arose from a single growth point but sometimes two chains were produced. As the first cell of the chain was formed the protoplast developed a vacuole (Fig. I $a$ ). The polarity shown by protoplasts producing a single chain is of interest but the mechanism involved is unknown. As regeneration proceeded the chain of cells lengthened (Fig. I $b, c$ ) and up to 20 cells were produced. Eventually the terminal cell produced a hypha (Fig. I d). This occurred after 1o h. in strain P76. The newly formed hypha lengthened, branched and ultimately gave rise to a new mycelium.

Freshly isolated protoplasts stained with calcofluor showed no fluorescence and thus were presumed to be free of wall material. This has since been confirmed by electron microscopic investigations (Gibson \& Peberdy, in preparation). Fluorescent material was seen around the cells formed during regeneration, and septa between the cells were also very distinct. The terminal cell of the chain which gave rise to the first hypha fluoresced most strongly.

Calcofluor stained preparations were submitted to osmotic shock by dilution with water. The chain cells lysed and the 'wall ghosts' produced continued to fluoresce but the terminal cell and the hypha remained intact. This osmotic sensitivity of the chain cells suggests that the wall material which they had produced was not rigid enough to act as a barrier against lysis.

The second type of regeneration is shown in Fig. 2a, $b, c$. The protoplast produced a new wall or 'shell' into which the cytoplasm migrated (Fig. 2a). As the chains lengthened the cytoplasm became divided into two parts situated at opposite ends of the chain.

The reason for the two types of regeneration is unknown, but the origins of the protoplasts may have been a factor. It is possible that the vacuolate protoplasts were those which produced the 'shell' type development. The third type of regeneration as reported by Garcia Acha et al. (1966) was not seen in our liquid regeneration cultures. However, in another series of experiments (R. K. Gibson, unpublished), the majority of $P 76$ protoplasts, when embedded in regeneration medium supplemented with $0.5 \%$ agar and cultured on microscope slides, did germinate directly to produce one or more germ tubes and under these conditions only a few chain structures were seen (Fig. I $f$ ). In this case the solid medium surrounding the protoplast may have provided the necessary support to allow hyphae formation whereas in liquid media this rigidity may have been achieved only by the development of the chain structures.

Some of the $24 \mathrm{~h}$. regeneration cultures were streaked onto malt extract agar plates. After a further $24 \mathrm{~h}$. at $25^{\circ}$ microcolonies were visible under a binocular microscope. These arose from the regenerated protoplasts (Fig. $2 d$ ). At this stage the germ tube had produced branches and distinct septa were present. On continued incubation these small colonies showed a typical mycelial form and ultimately produced conidia.

Our observations show that the potential to synthesize a new wall and revert eventually to the normal mycelial state is inherent in a proportion of the protoplasts released from Aspergillus nidulans hyphae. Clearly it is of interest to know whether inability to regenerate is due to the absence of a nucleus or to some other property of the cytoplasm.

J.F.P. thanks the Science Research Council for their support of this work, Miss Jane Marson for technical assistance and Mr Brian Case for photographic work. R.K.G. is supported by a Science Research Council Research Studentship. 


\section{REFERENCES}

BACHMAN, B. J. \& BonNer, D. M. (1959). Protoplasts from Neurospora crassa. Journal of Bacteriology 78 , 550-556.

Emerson, S. \& Emerson, M. R. (1958). Production and reversion of protoplast-like structures in the osmotic strain of Neurospora crassa. Proceedings of the National Academy of Sciences, U.S.A. 44, 668-67I.

Garcia ACha, I., Lopez-Belmonte, F. \& VillanUeVA, J. R. (I966). Regeneration of mycelial protoplasts of Fusarium culmorum. Journal of General Microbiology 45, 515-523.

NAGATA, T. \& TAKEBE, I. (1970). Cell wall regeneration and cell division in isolated tobacco mesophyll protoplasts. Planta (Berlin) 92, 30I-308.

Peberdy, J. F. (1971). Protoplasts from Mortierella vinacea. Transactions of the British Mycological Society $56,67-72$.

Rodriguez Aguirre, J., Garcia Acha, I. \& Villanueva, J. R. (1964). Formation of protoplasts of Fusarium culmorum by Strepzyme. Antonie van Leeuwenhoek 30, 33-44.

ZaLoKAR, M. (1959). Growth and differentiation of Neurospora hyphae. American Journal of Botany 46, 602-6ro. 